\title{
Method Data Envelopment Analysis for Estimating of Efficiency in Indication of Poverty
}

\author{
Aida Guliyeva *, Ulviyye Rzayeva** \\ *(Department of Information economy and technologies, The Azerbaijan State University of Economics, Baku, \\ Istiglaliyyet, 6 \\ ** (Department of Information economy and technologies, The Azerbaijan State University of Economics, \\ Azerbaijan
}

\section{ABSTRACT}

This paper studies the pattern of poverty, discusses various strategies of poverty reduction. The level of poverty is being analyzed according to various criteria. In this paper we propose to build the changes in relevant indicators of poverty level on the basis of various programs such as targeted social support. Method of Data Envelopment Analysis which operates with the concepts of economics and system analysis is being implied in this economic study.

Keywords: consumer basket, indicator, optimization, poverty, welfare

\section{INTRODUCTION}

The problem of poverty is one of the most important in the world. Under poverty meant the inability to provide elementary living conditions, available for most people in this country. Large scales of poverty, particularly in developing countries, represent a serious threat not only to national, but also for the world's sustainable development. Due to objective reasons, poor population cannot receive or process (due to the low level of education) required information. Consequently, this reduces the probability of solider and conscious action of these groups on the institutional market. Moreover, due to the asymmetry of information distributed between the various layers (or groups) of the population, it may actuate the mechanism of adverse selection. Adverse selection will facilitate the selection of economic, political and social institutions, which will aggravate the situation of poor people.

In most countries in Europe and Central Asia with developing and transition economies absolute indicator of income poverty is defined relative to the income required to acquisition of the minimum basket of consumer goods (which is determined by the social or biological point of view). The number of countries in the region, in which statistical agencies also report data, based on metrics of multidimensional poverty, is growing: as a rule, there are aggregate indicators that combine various elements of level of poverty measurement by income/material deprivation.

Human Development Index and the associated group of indicators constituting by the United Nations Development Program can also be considered as a statistical tool of measuring of multidimensional poverty. These indicators can also supplement the subjective assessments of poverty, indicators of lack of time and other tools. Traditional statistical approach is characterized by comparing each element with some "average" indicator. In contrast, the method of Data Envelopment Analysis (DEA) involves the comparison of each element with only comparable analogue.

\section{SOCIO-ECONOMIC INDICATORS OF POVERTY}

Generally, if inequality characterizes a society, then poverty concerns only part of the population. Depending on the level of economic development, poverty covers a large or a small part of the population. The proportion of the population (usually expressed as a percentage) living in official poverty, social scientists call "scale of poverty". The term "poverty threshold" is used to denote poverty.

Poverty threshold is the amount of money (usually expressed, for example, in US dollars), officially established as the minimum income, due to which an individual or family is able to buy food, clothing and shelter. It is also called as "poverty level".

A unified approach to the definition of "poverty" is not currently produced in the world statis tical practice. International practice uses several methods to determine the level of poverty. The most common way to measure poverty is based on income and consumption levels. A person is considered poor if his level of consumption or income is below a certain minimum level required to satisfy basic 
needs. This minimum level is usually called as the "poverty line".

Distinction is made between absolute and relative poverty in sociology. Under absolute poverty meant a condition in which an individual is able to satisfy only the minimum requirements to ensure biological survival. Under the relative poverty meant the inability to maintain the level of beseeming life or a certain standard of living, adopted in the community. Relative poverty shows just how an individual is poor in comparison with other people. This paper analyzes the condition of absolute poverty through the DEA method.

The concept of absolute poverty is based on the poverty line, namely on such level of income (or consumption), at which the family is not able to buy the necessary life-sustaining food and other essentials to the minimum necessary. This concept is widely used for international comparisons and for national poverty estimates.

There are the following criteria of an estimation of poverty. The subsistence minimum is a measure of the volume and structure of consumption of the most important material benefits and services at a minimum level necessary to maintain the active physical condition of the adult, social and physical development of children and adolescents.

The subsistence minimum is used as criterion for assessing the number of poor people. In Azerbaijan for this purpose trait (line) of poverty is used. Rapid economic growth, which was observed in Azerbaijan in the last decade, unfortunately, has not resulted in a drastic reduction of poverty and inequality among the population. For 2015 the table share of the poor population in Azerbaijan among 129 countries of the world estimates the share of the poor in $49 \%$.

In some countries, three threshold value of poverty are used:

- food line;

- lower common trait (the proportion of food consumption is $70 \%$ of the cost of the consumer basket);

- upper common trait (the proportion of food consumption is $56.5 \%$ of the consumer basket cost).

The composition of the "consumer basket" for the calculation of the minimum subsistence level is developed and approved by the relevant governmental and legislative authorities. In Azerbaijan, the food portion of the consumer basket is based on consumption norms developed by the National Institute of Nutrition. Sets products are calculated for individual socio-demographic groups In most countries the rate of consumption of basic foodstuffs are designed to the physiological needs of energy and nutrients recommended by experts from the Food and Agriculture Organization and the World Health Organization. In some countries, where the government cannot provide financial support to all persons with incomes below the subsistence minimum, additional criteria for evaluating the poorest part of the population are used. For example, for the provision of targeted social assistance in Azerbaijan, annually "need criteria" is approved, amounting to about $80 \%$ of the minimu m subsistence level.

\section{III.DEA AS A METHOD OF MODELING OF SOCIAL INDICATORS AND POVERTY}

In the economic system each sphere can be viewed as an object which produces the product using the internal operations by transforming resources. Overall productivity is desired to obtain in the form of ratio of the sum of products at the output by the sum of the resources at the input. Unfortunately, values of measurement of products and resources have different nature and dimension, making it impossible for their direct summation.

DEA operates with the concepts of economics and system analysis and can be used for economic research. This method was first proposed in 1957 by M. Farrell [1] and elaborated group of authors in 1978 [2] and in 1984 [3]. At the same time it was coined the term DEA. Nowadays published hundreds of studies that use this method to analyze the effectiveness of the state, regions and municipalities. Below we will consider the possibility of the DEA, as a method of estimation of efficiency in the poverty level indication.

The statistical study of human welfare indicators used for assessment of absolute and relative poverty, is based on the materials of the household budget surveys that allow analyzing the process of distribution and social differentiation of the population by the level of material wealth, as well as information about living conditions of different population groups. Each country decides what to use as the main criterion of material well income or expense [4]. Relevant indicators of poverty in this paper we propose to build on the basis of distribution of public expenditure (rather than income, as is usually done), dictated by the specifics of the transition period of the Azerbaijan.

Although development and implementation of poverty scale reduction strategies require a large investment, they have different effectiveness. To these authors relate:

1. Determination of target groups - low-income families, large families, families with disabled people, families with unemp loyed people;

2. Coverage of vulnerable population categories children from poor rural families, single women with children, lonely elderly citizens; 
Determination of such geographical subjects in which the acceleration of absolute poverty reduction is real. As an indicator of the level of poverty we consider the class

$$
I(\omega(x), f(x))=\int \omega(x) f(x) d x,
$$

with lower and upper bounds, respectively, 0 and $z_{0}$, where $f(x)$ - density function of the distribution of annual income per capita, $z_{0}$ - the so-called "poverty line" (the minimum subsistence level), and the weight function $\omega(x)$ - continuous, differentiable, decreasing and convex downward on the interval $[0$, $z_{0}$ ] function (these properties are determined by the natural assumption that the transfer of money from poor to less poor will lead to the increase of indicator value (1)) [5].

Poverty alleviation programs should cover national strategies, descriptions of macroeconomic, structural and social measures and definitions of the relevant external financing needs. Next, we examine the impact of program adoption on the change of poverty level, for example, targeted social support.

Let $S$ - the amount allocated to the targeted social support for the poor population, is less than the amount of money that is needed for complete eradication of poverty [6]. And let $\varphi\left(X^{t}, K_{i}, D_{i}, N_{i} \mid S\right)$ function that specifies the distribution rule of the amount $S$ with parameter $X^{t}$ among population with expenditure per capita $X^{t}<z_{0}$ (for example, it may be a function of distribution density of the amount $S$ among the poor population), and $f\left(X^{t}, K_{i}, D_{i}, N_{i} \mid \varphi, S\right)$ - the density distribution of the population by total expenditure per capita, resulting after realization of social assistance in accordance with rule $\varphi\left(X^{t}, K_{i}, D_{i}, N_{i} \mid S\right)$. With this value of the poverty level indicator in the above type changes, namely:

$I\left(\omega(x), f\left(X^{t} \mid \varphi, S\right)\right)=\int \omega(x) f^{\prime}\left(X^{t}, K_{i}, D_{i}, N_{i} \mid \varphi, S\right) d x$.

System limitations specified in the following form

$$
\begin{cases}K_{i \min } \leq K_{i}\left(X^{t}\right) \leq K_{i \max }, & i=1, \ldots, k, \\ D_{i \min } \leq D_{i}\left(X^{t}\right) \leq D_{i \max }, & i=1, \ldots, d, \\ N_{i \min } \leq N_{i}\left(X^{t} \leq N_{i \max },\right. & i=1, \ldots, n\end{cases}
$$

where $X^{t}$ - vector, the components of which express the amount of money allocated for the targeted social support for the poor population during the period of time $t$;

$i$ - number of approaches used in the assessment of quality of life. This includes:

- longevity, measured by life expectancy at birth (for the minimum value 25 years are accepted, for the maximum - 85 years);

- the level of education, measured by the level of literacy of the adult population (from 0 to $100 \%$ ) and the combined gross enrollment coefficient of education;
- living standards, measured by the size of GDP per capita at purchasing power parity in US dollars [7].

$K_{i}-$ minimum social standards of consumption in a wide range. This includes:

- minimum wage and retirement pension at the level of the subsistence minimu m;

- construction of wages, taking into account the need for maintenance for the child;

- the elimination of the state exploitation of skilled labor in the public sector in the form of monopoly price of their labor;

- the introduction of a minimum standard tax deduction at the level of the subsistence minimu mof the employee and his dependents;

- ensuring of the availability for the population of consumer goods and socially significant services.

$D_{i}$ - minimum consumer basket (minimum set of food, nonfood goods and services necessary to maintain human health and ensure his activities);

$N_{i}$ - subsistence level (the valuation of the consumer basket, plus mandatory payments and fees).

In the light of the researched problem we apply the DEA method to ensure that the question of poverty is fully taken into account in programs and to use the resources to support the efforts provided by the poverty reduction strategies more effectively. Technology model of factors conversion in activities of power structures in society in generated results intended to reduce the level of poverty is the starting point in the construction of program effectiveness assessment. Many ways and strategies intended to reduce the poverty level serve mathematically as the general description of poverty as a complex system of processes. The elements of this set are the ordered pairs $(x, y)$ of combinations of the investments' vectors $x$ and economic and social improvement's indicators $y$ as results of programs. The vector $x$ specifies the minimum required set of food, housing, health care, education, transport, communications. Vector $y$ indicates positive changes in:

- Socio-medical field (disability, old age, high level of disease);

- demography (single-parent families, a large number of dependents in the family);

- educational qualification area (lack of education, insufficient professional training);

- foreign policy (military conflicts, forced migration);

- regional-geographic policy (unequal development of regions).

Suppose we have a set of $l$ relatively homogeneous $k$ linkages, each of which has $I$ inputs and $J$ outputs, the above limitations affect their choice. At the federal level, costs are measured by budget expenditure in certain social areas, and the 
results (outputs) are measured using indicators that reflect the impact of these expenditures on these regions. Thus, in the field of social security, this measure is the Gini coefficient [8].

In accordance with the above, DEA method defines the degree of influence of each factor on the minimization of the function (2) is the ratio of the weighted sum of outputs to the weighted sum of the inputs, or in the formal entry,

The degree of influence of the factor

$$
\begin{gathered}
k=\left(v_{1} y_{1 k}+v_{2} y_{2 k}+\ldots+v_{m} y_{m k}\right) /\left(u_{1} x_{1 k}+u_{2} x_{2 k}+\ldots\right. \\
\left.\ldots+u_{n} x_{n k}\right)
\end{gathered}
$$

where $u_{i}$ - dimension of the space attributed to inputs $i=1, \ldots, n ; x_{i k}$ - the value of input $i$ of factor $k=1, \ldots, l ; v_{j}$ - the dimension of the space attributed to the outputs $j=1, \ldots, m ; y_{j k}$ - the value of output $j$ of factor $k$. All dimensions allow conversion of each input and output in a dimensionless numerical form. In the traditional formulation the choice of the most powerful factor requires the appointment of a unified set of weights applicable to all $l$ linkages. This in turn raises the problem of acceptability of the set of weights for all objects. Firstly, it may be difficult to execute an a priori estimate of the importance of inputs and outputs. Secondly, various factors can have different effects according to the study of poverty from different angles, and various inputs/outputs will have different values from an organizational point of view [9].

The variables in the solution of this problem are the weights of inputs and outputs, and weights $h$, most suitable for the given linkage $k$ play the major role. Algebraically, this problem is written as:

$$
\max h_{S}=\Sigma v_{j} y_{j k} / \Sigma u_{i} x_{i k}
$$

under conditions

$$
\left(\sum v_{j} y_{j k} / \sum u_{i} x_{i k}\right) \leq 1
$$

for all $k$ and

for all $i, j$.

$$
\begin{aligned}
& u_{i} \geq 0, i=1, \ldots, n, \\
& v_{j} \geq 0, j=1, \ldots, m
\end{aligned}
$$

Assessment of the effectiveness of each of the selected object from the test set can be obtained by solving linear programming problems, which will form a set of weights that implement this efficiency. To compare the efficiency of all elements of the set it is necessary to solve the same problems, allowing choosing a favorable weights by turns. For any ineffective object at least one comparable object will be effective in the own selected system of weights. Effective in this sense elements form an equivalent effective group for the considered ineffic ient object.

\section{CONCLUSION}

DEA method can be very useful in the Decision Support Systems, when it is required to classify some objects based on the assessment of their effectiveness. In as sessing of complex systems concomitant problem of determining of the relative importance of the diverse indicators for the functioning of the system often occurs. Also, there are difficulties in obtaining single - integral efficiency indicators. In light of the investigated problem DEA method allows to avoid these complexities and makes it possible to obtain an integrated indicator of the effectiveness for each of the levels of poverty of the population included in the considered system, without requiring a priori assignment of weight coefficients for the variables.

\section{REFERENCES}

[1] M.J. Farrell, The Measurement of Productive Efficiency, J. of the Royal Stat. Soc. Ser. A (General), No 3, 1957, Vol. 120, pp. 253290.

[2] Charnes, W.W. Cooper, E. Rhodes, Measuring the Efficiency of Decision Making Units, Europ. J. of Operational Research, 1978, No 2, pp. 429-444.

[3] R.D. Banker, A. Charnes, W.W. Cooper, Some Models for Estimating Technical and Scale Inefficiencies in Data Envelopment Analysis, Management Science, No 30, 1984, pp. 1078-1092.

[4] E.P. Morgunov, The use of Data Envelopment Analysis in the analysis of the activities of health care institutions, Problems and prospects of the Russian economy, (Penza, 2002).

[5] J. Hentschel, P. Lanjouw, Constructing an Indicator of Consumption for the Analysis of Poverty, World Bank Living Standard Measurement Study, (124, Washington, DC, 1996).

[6] A . Hagenaars, Class of Poverty Indices, Interational Economic Review, No 28, 1987, pp. 583-607.

[7] A.I. Rossoshanski, Evaluation of quality of life: a review of methodological approaches, Young scientist, 2013, Nol1, pp. 440-445.

[8] D. Hauner, Benchmarking the Efficiency of Public Expenditure in the Russian Federation, IMF Working Paper, WP/07/246, IMF, October 2007.

[9] A. Kuznetsov, E. Kozlova. DEA method to study the efficiency of container terminals, International Maritime Journal, No 4, 2007, pp. 52-55. 